\title{
A SIMULATION STUDY FOR DESIGNING A RAIL TERMINAL IN A CONTAINER PORT
}

\author{
Byung Kwon Lee \\ Bong Joo Jung \\ Kap Hwan Kim \\ Dept. of Industrial Engineering \\ Pusan National University \\ Busan 609-735, KOREA
}

\author{
Soon Oh Park \\ Virtual Manufacturing System Solutions, Ltd. \\ Daejeon 305-701, KOREA
}

\author{
Jeong Hoon Seo \\ Digital Factory Research Center \\ Yeungjin College \\ Taegue 701-721, KOREA
}

\begin{abstract}
Rail terminals in port container terminals play an important role for transshipping containers between rail wagons and port container terminals. This paper addresses a case study for designing a new rail terminal which is planned to be constructed in a port container terminal. A design process including an analytical calculation and a simulation study was proposed. The analytical approach was used to estimate the facility size and the simulation was used to evaluate proposed design alternatives in more detail. Design parameters were the number of transshipment lanes, the number of cranes, and the traffic flows inside the rail terminal.
\end{abstract}

\section{INTRODUCTION}

In Korea, the train appeared on Seoul-Inchon Line in 1899. In 1996, the rail transportation shared $88.2 \%$ of transportation supply in Korea. However, the share rate has been going down steadily. The main reasons of the decrease were the complexity of the rail transportation process and difficulties in the door-to-door transportation. Also, an initial investment for the construction of rail transportation networks is enormous. However, operation costs per unit distance go down as the travel distance increases. And the rail transportation is an eco-friendly and highly stable transportation mode.

In general, there are three kinds of transportation mode for inland transportation from ports to inland cities. The first is the road way transportation by using trucks. The second is the rail transportation. The third is the water transportation by using ships. The road way transportation usually is used for short distance transportations and a door to door transportation. Rail transportations are used for long distance transportations and heavy freights transportation. The water transportations are used for long distance transportations and a large amount of freights.

Related to intermodal freight terminals, Ballis and Golias (2002) identified main design parameters for rail- road freight transport terminal, which is similar to the issue of this paper. They proposed length of transshipment tracks, the number of handling equipment, stacking height in the storage area as design parameters. Alicke (2002) modeled the transshipment operation in intermodal terminal by using an optimization model based on constraint satisfaction. Corry and Kozan (2006) addressed the load planning problem in intermodal rail terminals.

In field of container terminals, many studies have been done about designing problems. Steenken et al. (2004) provided an excellent literature review on container terminal operations and references containing the various optimization methods that have been used to solve these logistical problems. Kim and Kim (2002) discussed a method of determining the optimal amount of storage space and the optimal number of transfer cranes for handling import containers.

A recent trend of advanced ports in other countries is the construction of intermodal terminals in port areas. Because there exists a plan about Eurasia Railroad which transports freight from Korea to Europe, the rail transportation will become much more important than ever before in Korea. Many advanced container ports plan to expand the port area so that new conceptual rail terminals are constructed in the port area. Thus, efficient rail terminal operations and the optimized rail terminal design became important issues. However, little studies have been done about rail terminals.

This paper discusses a way of designing rail terminals by using a simulation technique and compares the resulting design alternative with those by numeric formulas for estimation of design parameters of rail terminals. Section 2 introduces rail terminals. Section 3 discusses design and operation issues in rail terminals and provides numeric formulas for estimation of the performance of rail terminals. In section 4 , the performance of yard trucks and cranes are analyzed and design alternatives are suggested. Section 5 evaluates each scenario by a simulation study. In section 6 , the conclusion is given. 


\section{DESCRIPTION OF RAIL TERMINALS}

A main purpose of rail terminals is to exchange the transportation mode of freight. Containers from inland cities are transferred to yard trucks or road trucks. Containers from abroad may be transferred to trains for transportation to inland destinations. These exchanges of the transportation mode are a role of rail terminals. A general structure of rail terminals is illustrated in Figure 1. There are four transshipment tracks under the rail crane. The term "transshipment track" is a rail track that can be served by handling equipment. Besides transshipment tracks, there is a waiting track, and a driving track. The waiting track enables trains to dwell in the terminal in case that there is no empty space in transshipment tracks or trains wait for departure signals. And the driving track is used for trains to run on. The transfer points (TPs) for yard trucks (YTs) are located at the side of transshipment tracks. There are two types of transfer operations in rail terminals: a direct transfer between a wagon and an YT; the indirect transfer via the temporary storage area. In the direct transfer, a container is transferred between an YT and a wagon directly. In the second type of transfer operations, a container is transferred via the temporary storage area. The operation of the second type happens when the assigned YT did not arrive at the TP or the assigned YT was not ready to receive a container.

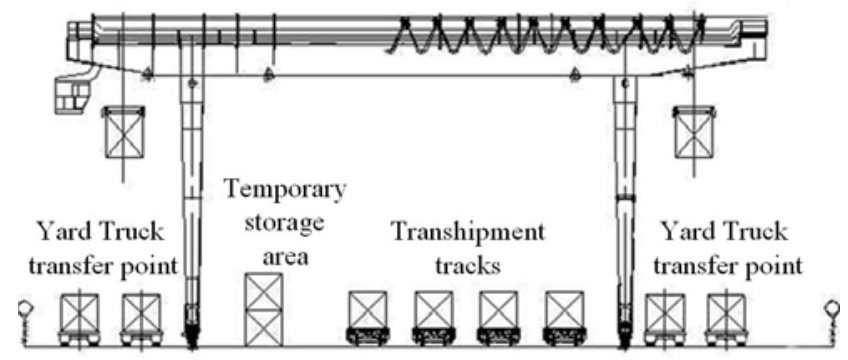

Figure 1: Illustration of Tracks of Rail Terminals and a Rail Crane Deployment

The transfer operation in rail terminals usually starts after the arrival of a train or after the starting time of a shift (in the case that trains arrived at the terminal during the mid night). For example, the unloading process will be explained. When an YT arrived, a direct transshipment from a wagon to a truck is carried out. However, if the assigned YT is not ready at the transfer lane, the crane picks up a container from a wagon and stacks the container into the temporary storage. The crane may transfer a container from the temporary storage to the YT. If the arrived YT brings an outbound container, then the crane must transfer first the outbound container from the YT to a wagon. And then the crane transfers a container from the temporary storage or a wagon to the YT. Although cranes are the most popular equipment in rail terminals, some small-sized rail terminals use reach stackers for container handling.

\section{A PROCESS AND ISSUES FOR DESIGNING RAIL TERMINALS}

This paper addresses a design problem for two rail terminals which are supposed to be constructed in a container port. This paper proposes design and operation issues which were observed in the case study. Two important design issues are to determine the number of transshipment tracks and the number of cranes. Three important operational issues were to determine the flows of YTs within rail terminals, operation processes of YTs and cranes, operation plans for trains.

The overall design process is given in Figure 2. First, the target rail transport requirements must be determined. Second, design parameters of the rail terminal must be estimated based on rail transport requirements. Third, the layout plans for the rail terminal facilities must be constructed based on estimated design parameters. Fourth, a simulation model must be constructed considering the terminal layout and design parameters. This simulation model is tested by using various scenarios which may consider various design issues and operational issues. After the simulation study, the tested scenarios are analyzed and evaluated. Figure 3 illustrates the overall layout of the container port.

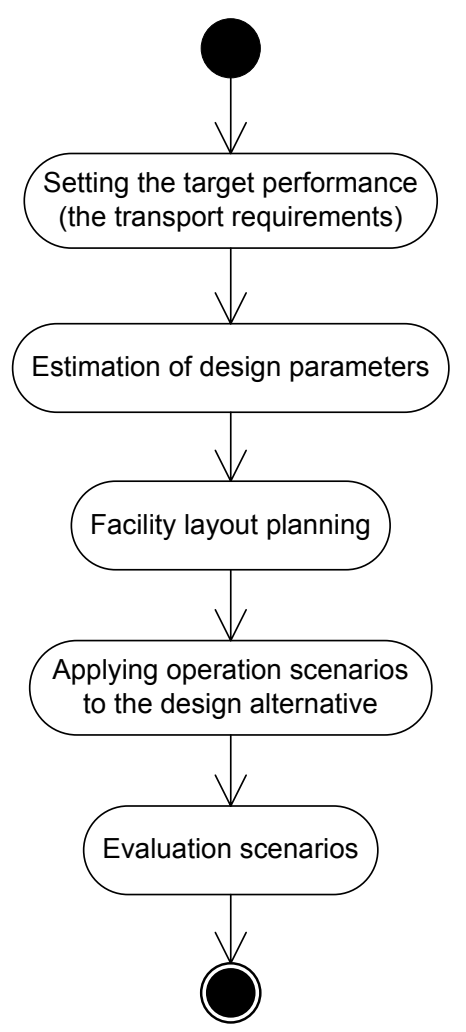

Figure 2: Process of Rail Terminal Design 
Hinterland

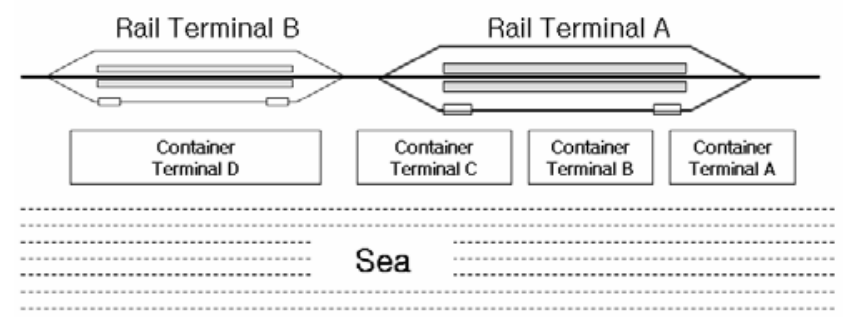

Figure 3: Layout of Port Container Terminals \& Rail Terminals

\subsection{Performance requirements of the rail terminal}

The rail terminal may be constructed to serve a specific container terminal. Otherwise, the rail terminal may be a public terminal which can serve multiple port container terminals or nearby industrial parks. There are two decision-making problems. One is how many rail terminals are to be constructed, and the other is where it (or they) should be located. This paper assumes that there are two rail terminals and they are located between four port container terminals and industrial park as shown in Figure 3. The total throughput requirement of the rail terminal is $430,000 \mathrm{TEU}$ per year. The rail terminal must handle containers from/to four port container terminals. The two rail terminal will be called 'Rail terminal A' and 'Rail terminal B,' respectively.

Rail terminals A and B are linked with one driving track. When it was determined that two rail terminals will be constructed, the first thing to do was to allocate container flows from/to port container terminals to either of the two rail terminals based on a distance or some criterions. It was assumed that container terminal $\mathrm{A}, \mathrm{B}$, and $\mathrm{C}$ is served by rail terminal $\mathrm{A}$ and container terminal $\mathrm{D}$ is served by rail terminal $\mathrm{B}$. In accordance with this the assignment, 280,000 TEU was assigned to rail terminal A and 140,000 TEU was assigned to rail terminal B. And this paper focuses on the design problem of rail terminal A.

\subsection{Formulas for determining values of design parameters}

Important design parameters are the number of transshipment tracks and cranes. These two parameters can be estimated by using numerical formulas before making a simulation model. Numerical formulas for estimating the values of the parameters are shown in Table 2. The number of transshipment tracks and cranes are estimated by using these formulas. These design parameters are used for designing layouts of rail terminals. Table 1 shows constant parameters to estimates design parameters. Rail terminal A has the values of constant parameters as shown in Table 3 . Table 4 shows estimated values of design parameters. In summary, it was concluded that rail terminal A needs at the minimum 2 rail cranes and 3 transshipment tracks.
Table 1: Constant Parameters to be Used for Determining Design Parameters

\begin{tabular}{|c|l|}
\hline Notations & \multicolumn{1}{|c|}{ Description } \\
\hline$T$ van & $\begin{array}{l}\text { The handling capacity of the crane per hour } \\
\left(1 / C_{t}\right)\end{array}$ \\
\hline$\eta T$ & The utilization of the crane \\
\hline$W y$ & The number of workdays per year \\
\hline$W d$ & Working hours per day \\
\hline$T E U f$ & $\begin{array}{l}\text { TEU factor to convert the number of containers } \\
\text { to TEU }\end{array}$ \\
\hline$C T E U$ & Transport requirement per year (TEU) \\
\hline$F p$ & Peak factor \\
\hline$D L$ & Ratio of the direct transportation \\
\hline$N R$ & The average number of wagons per train \\
\hline$T r o t$ & Time for the locomotive operations \\
\hline
\end{tabular}

\subsection{Facility layout planning}

This section plans the layout of rail terminal A based on estimated design parameters in section 3.2. The layout of rail terminal A is shown in Figure 4. Rail terminal A is composed of two operation areas. One operation area is located toward the hinterland, and the other operation area is located at the side of the container port. In Figure 4, one driving track is provided in the middle of the terminal. The driving track links rail terminal $\mathrm{A}$ and rail terminal $\mathrm{B}$ and used for trains to pass the terminals. And one waiting track is provided at the side of the hinterland. In rail terminal A, five transshipment tracks are planed. Three transshipment tracks are located at the side of the container port and two tracks are located at the side of the hinterland. In section 3.2 , the number of transshipment tracks was determined to be three. However, we planned two additional transshipment tracks considering possible future growth of the handling requirement in the rail terminals. There are two gates for YTs to enter. YT lanes were provided around operation areas. YTs drive along these lanes. And one rail crane is planned to be installed at each operation area.

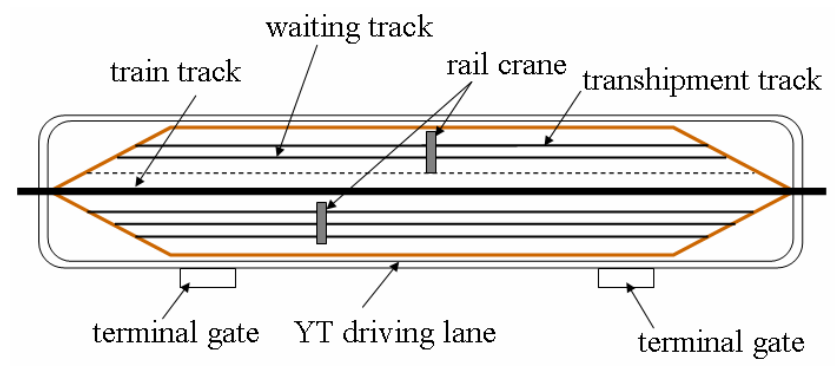

Figure 4: The Layout of Rail Terminal A 
Table 2: Formulas for Determining the Values of Design Parameters

\begin{tabular}{|c|c|}
\hline Notations & Description \\
\hline Avan & $\begin{array}{c}\text { Effective handling capacity of a crane per hour } \\
\qquad \text { Avan }=T \operatorname{van} \times \eta T\end{array}$ \\
\hline$C V$ & $\begin{array}{l}\text { Transport requirement in the number of contain- } \\
\text { ers (van) } \\
\qquad C V=\frac{C T E U}{T E U f}\end{array}$ \\
\hline Cea & $\begin{array}{l}\text { The number of cranes required (design parame- } \\
\text { ter) } \\
\qquad C e a=\frac{C V \times F p}{A v a n \times W d \times W y}\end{array}$ \\
\hline$Y H C$ & $\begin{array}{l}\text { Handling capacity of cranes per year } \\
\qquad Y H C=A \operatorname{van} \times W d \times W y \times C e a\end{array}$ \\
\hline$D H C$ & $\begin{array}{l}\text { The number of loading and unloading containers } \\
\text { per day } \\
\qquad D H C=\frac{C V \times F p}{W y}\end{array}$ \\
\hline$T H C$ & $\begin{array}{l}\text { Handling capacity of a crane per day } \\
\qquad T H C=A v a n \times W d\end{array}$ \\
\hline Chf & $\begin{array}{l}\text { The average number of handlings per container } \\
\qquad C h f=D L+\{(1-D L) \times 2\}\end{array}$ \\
\hline Trteu & $\begin{array}{l}\text { The loading capacity per train (TEU) } \\
\text { Trteu }=N R \times 2(T E U)\end{array}$ \\
\hline Trvan & $\begin{array}{l}\text { The loading capacity per train in the number } \\
\text { containers } \\
\qquad \text { Travn }=\frac{\text { Trteu }}{\text { TEUf }}\end{array}$ \\
\hline Trhc & $\begin{array}{l}\text { The handling capacity of a crane (in TEU) per } \\
\text { hour } \\
\qquad T r h c=T E U f \times A v a n\end{array}$ \\
\hline Trht & $\begin{array}{l}\text { Loading and unloading time per train by a crane } \\
\qquad \operatorname{Trht}=\operatorname{Trteu} / \operatorname{Trhc}\end{array}$ \\
\hline Trtot & $\begin{array}{c}\text { Total service time per train by a crane } \\
\text { Trtot }=\text { Trht }+ \text { Trot }\end{array}$ \\
\hline$D d t n$ & $\begin{array}{l}\text { The number of trains per day that arrive at the } \\
\text { rail terminal } \\
\qquad D d t n=\frac{D H C}{\text { Trvan }}\end{array}$ \\
\hline Dtn & $\begin{array}{l}\text { The number of assigned trains per day per track } \\
\qquad D t n=\frac{W d}{\text { Trtot }}\end{array}$ \\
\hline Dntn & $\begin{array}{l}\text { The required number of transshipment tracks } \\
\text { (design parameter) } \\
\qquad D n t n=\frac{D d t n}{D t n}\end{array}$ \\
\hline
\end{tabular}

\section{A SIMULATION STUDY}

\subsection{Simulation modeling}

A simulation model was constructed by using the terminal layout in Figure 4. Figure 5 show the entire process of the
Table 3: Input Values of Constant Parameters of Rail Terminal A

\begin{tabular}{|c|l|}
\hline Notations & \multicolumn{1}{|c|}{ Input Values } \\
\hline$C t$ & $82.3 \mathrm{~s}$ \\
\hline$T v a n$ & $43.5 \mathrm{vans} / \mathrm{hr}$ \\
\hline$\eta T$ & 0.45 \\
\hline$W y$ & 330 day / year \\
\hline$W d$ & $20 \mathrm{hr} /$ day \\
\hline$T E U f$ & 1.48 \\
\hline$C T E U$ & 280,000 vans / year \\
\hline$F p$ & 1.25 \\
\hline$D L$ & 0.6 \\
\hline$N R$ & 25 \\
\hline
\end{tabular}

Table 4: Design Parameters of Rail Terminal A

\begin{tabular}{|c|l|}
\hline Notations & \multicolumn{1}{|c|}{ Output Values } \\
\hline Cea & 2 cranes \\
\hline$Y H C$ & 258,390 vans per year \\
\hline$D H C$ & 726.4 vans per day \\
\hline$D d t n$ & 21.36 trains per day \\
\hline$D t n$ & 7.27 trains/day/track \\
\hline$D n t n$ & 3 tracks \\
\hline
\end{tabular}

simulation model in this study. First, a train arrives at the rail terminal and then every YT starts to depart from its container terminal to the dedicated rail terminal. It was assumed that all the YTs are available when the simulation starts. The rail cranes at each rail terminal have an operational rule which is called 'unidirectional traveling rule,' in which a crane travels in the same direction, transferring containers from/to trucks, until no truck is available in the direction of the travel. When no truck to serve can be found in the direction of the travel, the crane changes its travel direction.

The number of train arrivals per day is calculated by the equation for Ddtn in Table 2. Inter-arrival time of trains is generated randomly by using the triangular distribution.

Rail terminal A is the last terminal in the main railroad track as shown in Figure 1 and a single track passes rail terminal A and rail terminal $\mathrm{B}$. Therefore, a train must return on the same track after finishing the load/unload operations at a rail terminal. Furthermore, all operators work for 20 hours a day at each rail terminal. Also, it was assumed that a time window is given during which trains are allowed to run on the main track. The maximum range of the time window is 20 hours. Trains which arrived after the end of the time window must wait until the beginning the time window of the next day. Also, a train which completed the transfer operation cannot depart each rail termi- 
nal unless it is within the time window. The train operation described above is shown as Figure 6.

Figure 7 shows the operation process of YTs. Two types of events happen when an YT arrives at the TP (transfer point). If the TP is empty, then the YT enters the TP. However, when the YT can not enter the TP, it searches for a parking position in the neighborhood of the TP. If there is a parking position, then the YT parks at the position and waits until the entrance to the TP is allowed. If there is no parking position in the neighborhood of the TP, then the YT parks at the YT driving lane. This situation may incur congestion at the YT driving lane. By these congestions, the performance of the rail terminal may decline. Thus, the flow of YTs is an important issue in the operation of rail terminals.
Thus, three alternative types of YT flows are proposed: flows dedicated to each container terminal (dedicated flow); flows selectively dedicated to each container terminal (selective flow); flows mixed by the dedicated and selective flows (mixed flow).

Next, the operation of a rail crane was analyzed. Figure 8 shows the operation process of the rail crane. Cranes are assumed to sequence transfer tasks in the increasing order of the travel distance from the position of the crane to the position of each task to the direction of the driving of the crane. If there is no task in the driving direction, then the crane drives to an opposite direction. If no YT is in the terminal, the crane transfers inbound containers from wagons onto the temporary area during its idle time.

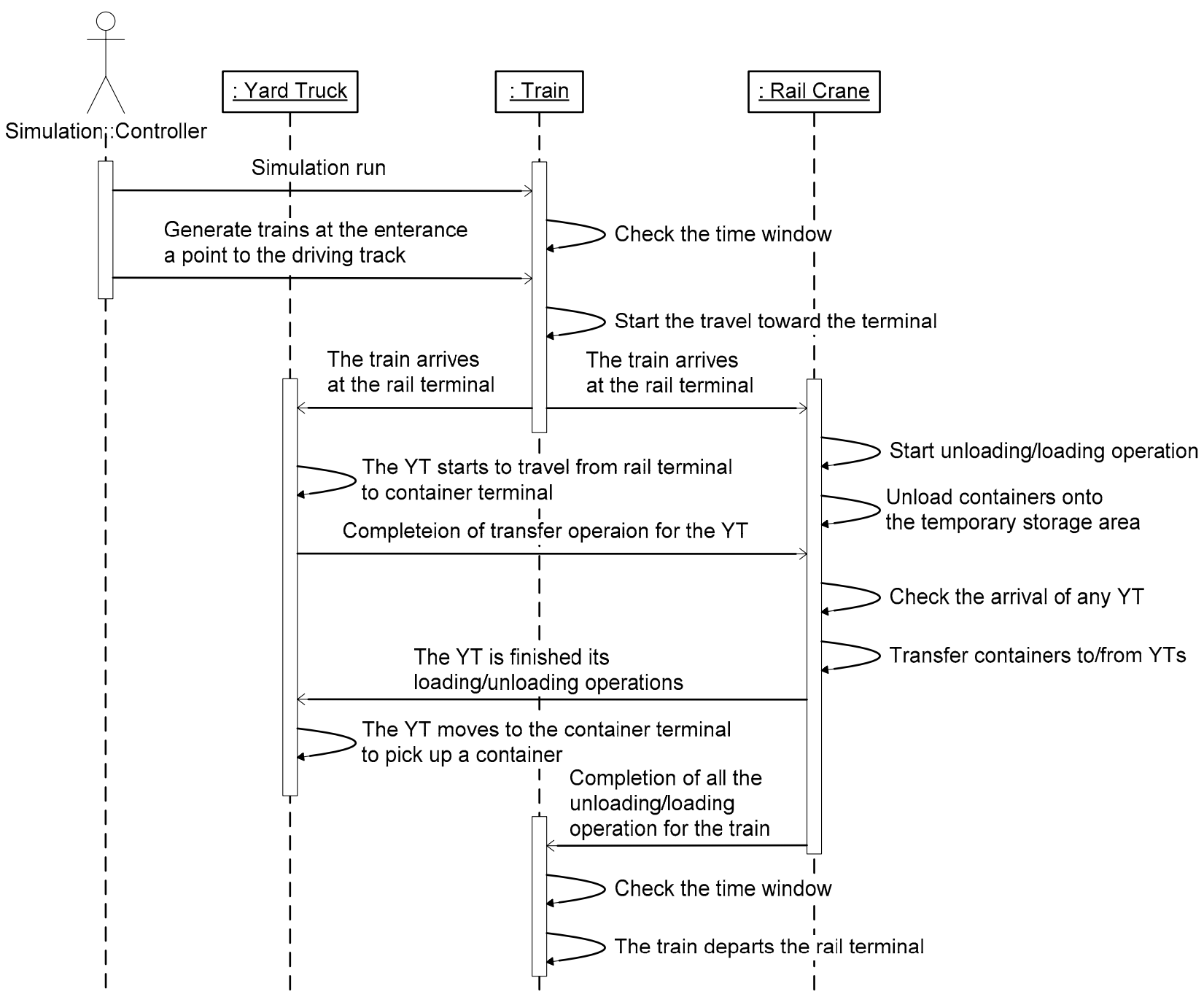

Figure 5: The Sequence Diagram for Rail Terminal Simulation 
Lee, Seo, Park, Jung, and Kim

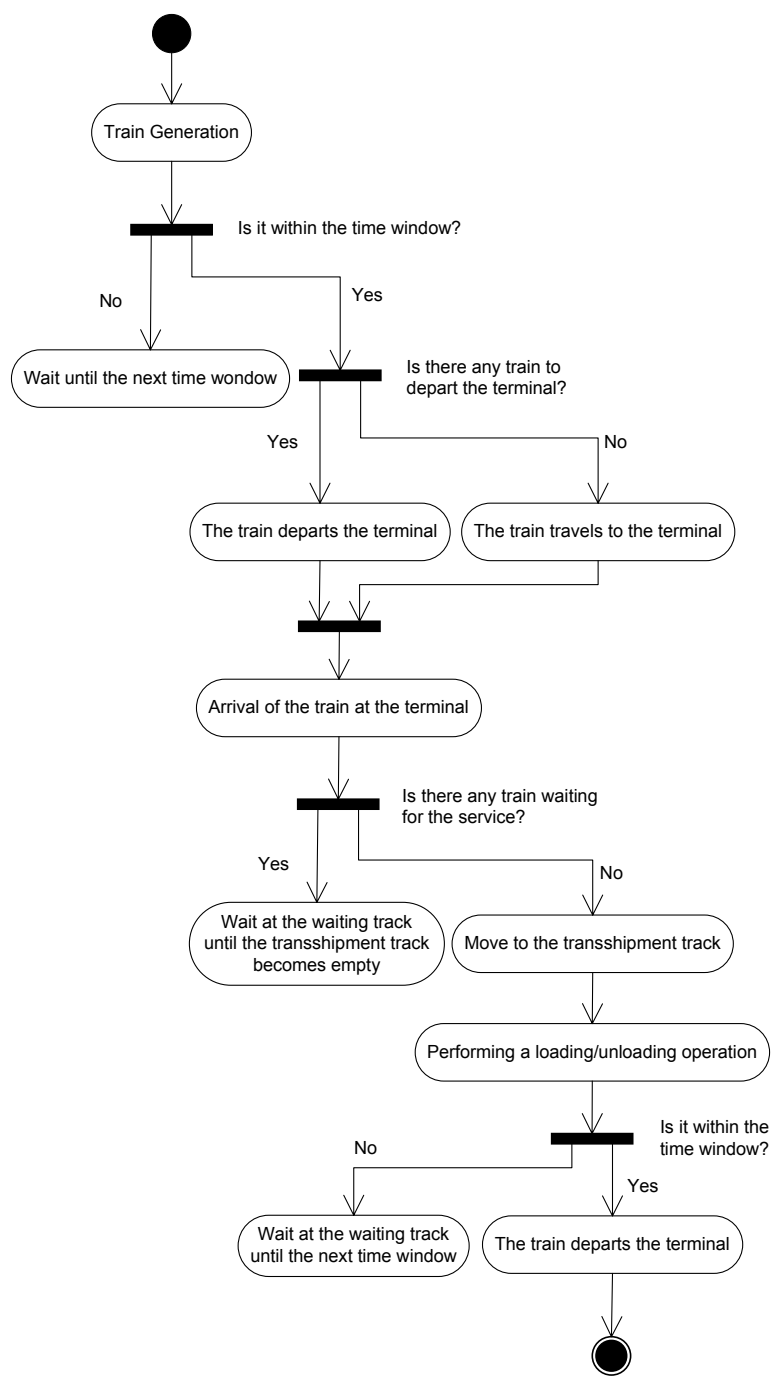

Figure 6: Train Operation

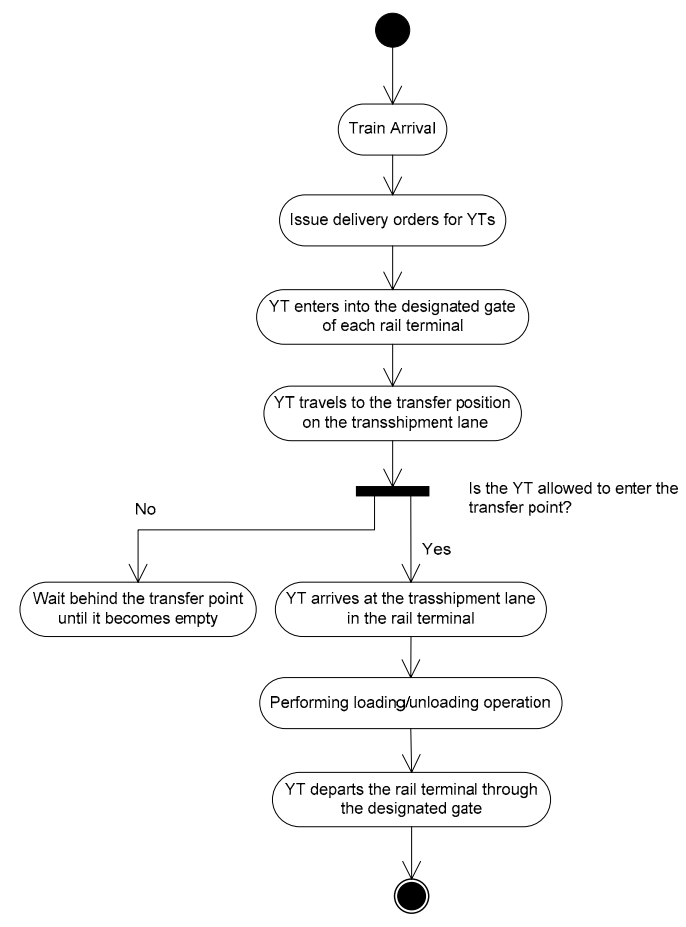

Figure 7: YT Operation

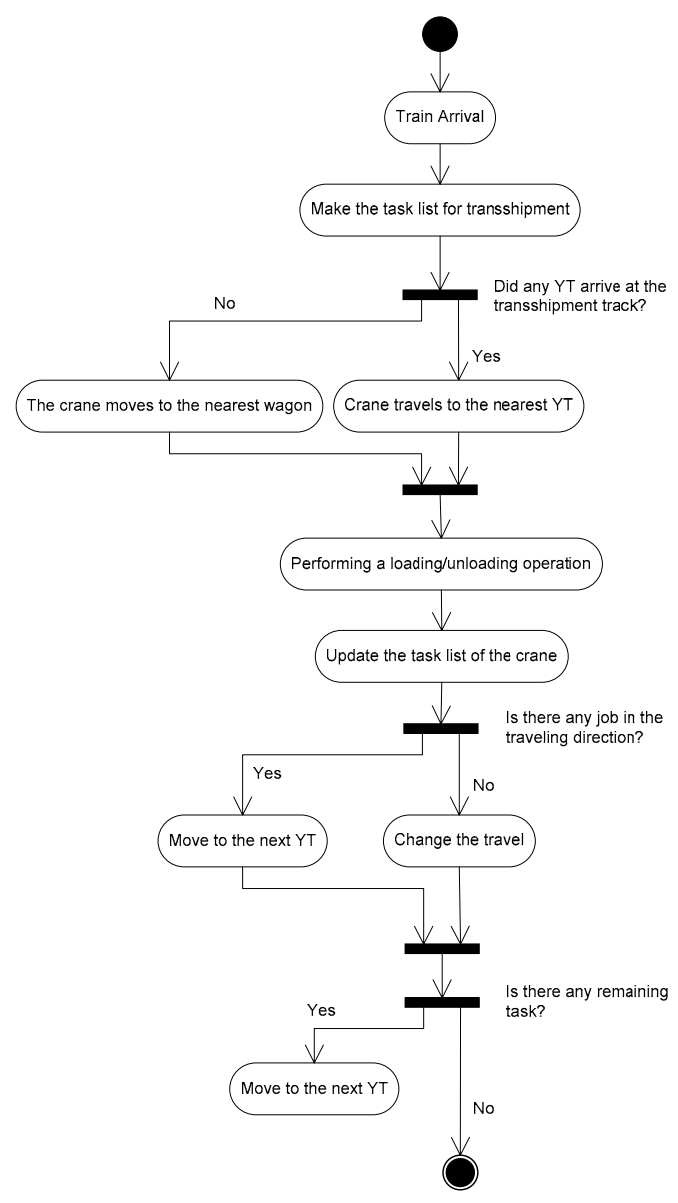

Figure 8: Rail Crane Operation 


\subsection{Simulation testing scenarios}

We restricted the flows by allowing YTs to drive only counter-clockwise within the rail terminal. In the dedicated flow, YTs from a specific container terminal are assigned to a specific entrance gate. Figure 9 and 10 shows YT flows depending on the operation position of an YT. YTs from terminal A and B can enter the rail terminal only through the right gate. And YTs from terminal $\mathrm{C}$ can enter the rail terminal only through the left gate.

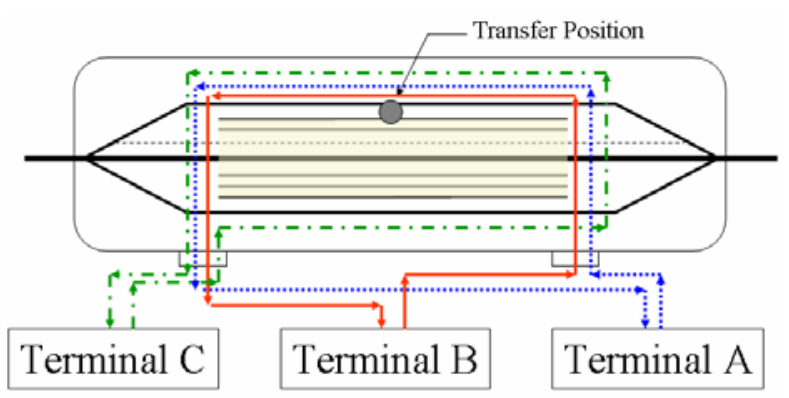

Figure 9: Dedicated Flows When the Transfer Position is Located at the Side of the Hinterland

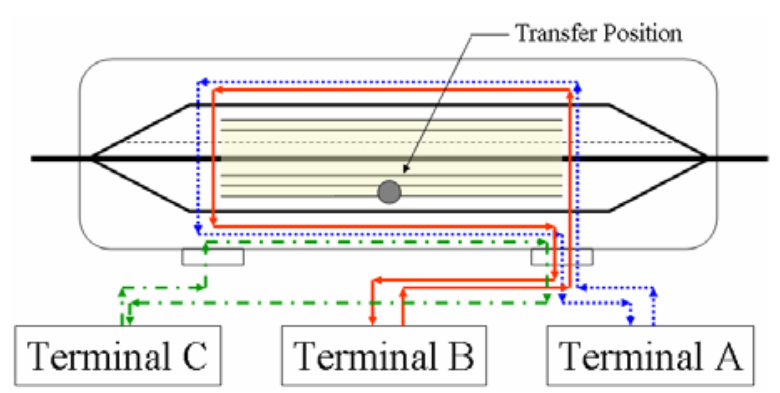

Figure 10: Dedicated Flows When the Transfer Position is Located at the Port Side

In the selective flow, the entrance gate of a YT depends on the transfer position. If the transfer position is located at the hinterland side, then the YT is assigned to the right gate. On the contrary, if the transfer position is located at the port side, then the YT is assigned to the left gate (refer to Figure 11 and 12).

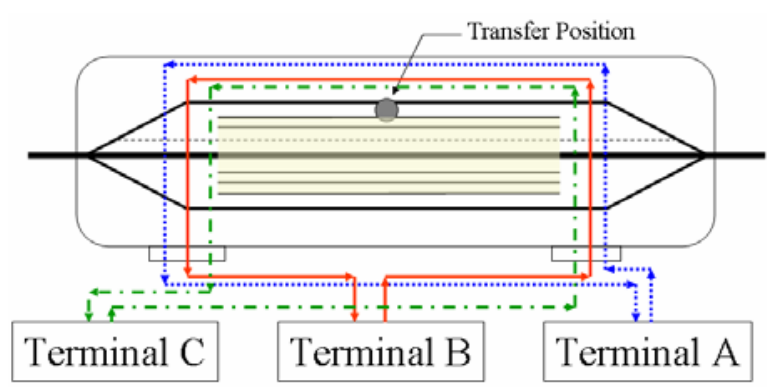

Figure 11: Selective Flows When the Operation Position is Located at the Hinterland Side

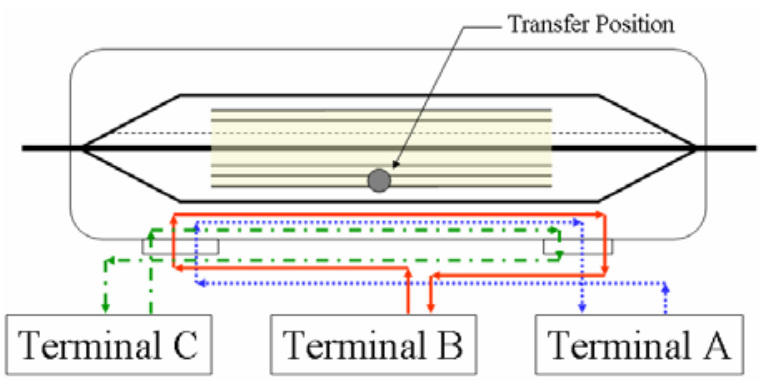

Figure 12: Selective Flows When the Operation Position is Located at the Port Side

In the mixed flow, the flows of YTs from terminal A and $\mathrm{C}$ is the same as the case of the dedicated flow. However, the flows of YTs from terminal B depend on the transfer position. If the transfer position of a YT from terminal B is located at the hinterland side, then the right entrance gate is assigned to the YT (refer to Figure 13). On the contrary, if the transfer position of a YT from the terminal B is located at the port side, then the left entrance gate is assigned to the YT (refer to Figure 14).

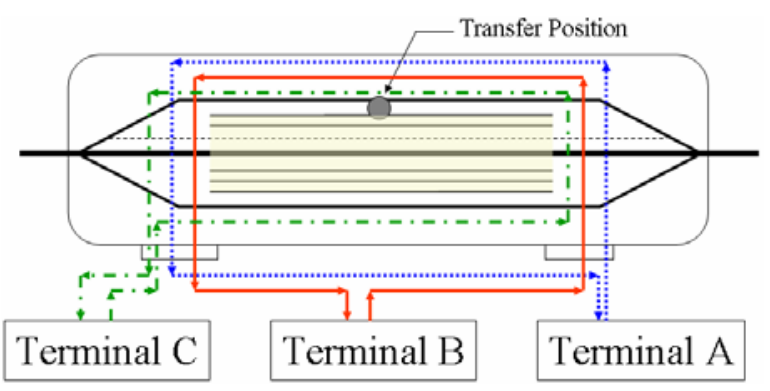

Figure 13: Mixed Flows When the Operation Position is Located at the Hinterland Side

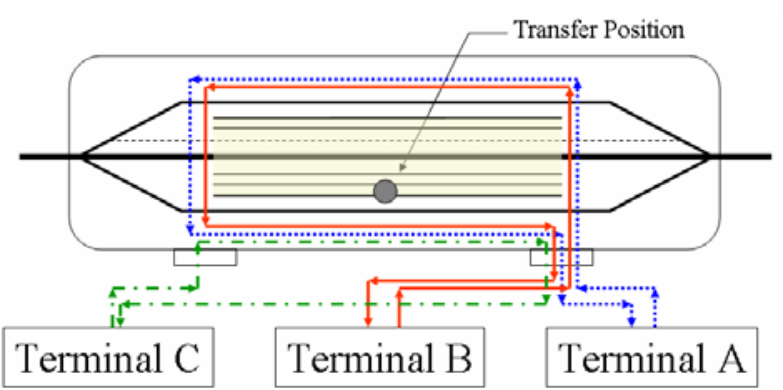

Figure 14: Mixed Flows When the Operation Position is Located at the Port Side

We assumed two different scenarios on the operation times of rail terminals per day. The first scenario assumes that trains can run on a track within the time window of 20 hours per day, which is rather unrealistic. If the limited availability of tracks for trains to/from the rail terminal is considered, then the second scenario in which the length of the time window for train arrivals is shorter than 20 hours per day seems to be more reasonable than the first scenario. 
The second scenario assumed the driving track for trains are available for only 7 hours. We used the second scenario for estimating the number of transshipment tracks required.

Several scenarios considering above mentioned factors were proposed for estimating design parameters. Table 5 shows the seven scenarios. Scenarios A, B and C are used to compare three types of the YT flows. Scenarios D and E are used to test the effect of the number of rail cranes. Scenario $F, G$ and $\mathrm{H}$ are used to evaluate the effect of the number of transshipment tracks on the system performance. All the experiments were conducted by using the simulation model for rail terminal A.

Table 5: Design Parameters of Each Scenario

\begin{tabular}{|c|c|c|c|c|c|c|}
\hline \multirow{2}{*}{$\begin{array}{c}\text { Sce- } \\
\text { nario }\end{array}$} & \multirow{2}{*}{$\begin{array}{c}\text { YT } \\
\text { flows }\end{array}$} & $\begin{array}{c}\text { Time - } \\
\text { widow } \\
\text { for } \\
\text { train } \\
\text { arrival }\end{array}$ & \multicolumn{2}{|c|}{$\begin{array}{c}\text { The number of the } \\
\text { transhipment } \\
\text { track }\end{array}$} & \multicolumn{2}{|c|}{$\begin{array}{c}\text { The number of } \\
\text { cranes }\end{array}$} \\
\cline { 4 - 7 } & & $\begin{array}{c}\text { Terminal } \\
\text { A }\end{array}$ & $\begin{array}{c}\text { Terminal } \\
\text { B }\end{array}$ & $\begin{array}{c}\text { Terminal } \\
\text { A }\end{array}$ & $\begin{array}{c}\text { Terminal } \\
\text { B }\end{array}$ \\
\hline A & Dedicated & 20 (hrs) & $3-2^{*}$ & 3 & $1-1 *$ & 1 \\
\hline B & Selective & 20 & $3-2$ & 3 & $1-1$ & 1 \\
\hline C & Mixed & 20 & $3-2$ & 3 & $1-1$ & 1 \\
\hline D & Mixed & 20 & $3-2$ & 3 & $1-1$ & 1 \\
\hline E & Mixed & 20 & $3-2$ & 3 & $2-1$ & 0 \\
\hline F & Mixed & 7 & $3-3$ & 3 & $1-1$ & 1 \\
\hline G & Mixed & 7 & $3-2$ & 3 & $1-1$ & 1 \\
\hline H & Mixed & 7 & $3-0$ & 3 & $1-1$ & 1 \\
\hline
\end{tabular}

*: A-B : A is the number of cranes at the port side, $\mathrm{B}$ is the number of cranes at the hinterland side

\section{EVALUATION OF SCENARIOS}

\subsection{Comparing scenarios $(A, B, C)$ with different flows of YTs}

The purpose of this experiment is to compare performances of three types of the YT flows. Simulation results are shown in Figure 15. In scenario A, much congestion was generated. These congestions resulted in the increase of the average YT traveling time. In scenario B, little congestion was generated. However, all YTs entered the train terminal through one gate. By this reason, there is a long waiting line in front of the gate. This congestion increased the average YT traveling time. Scenario $C$ showed little congestion inside the terminal and a short waiting in front of the gate.

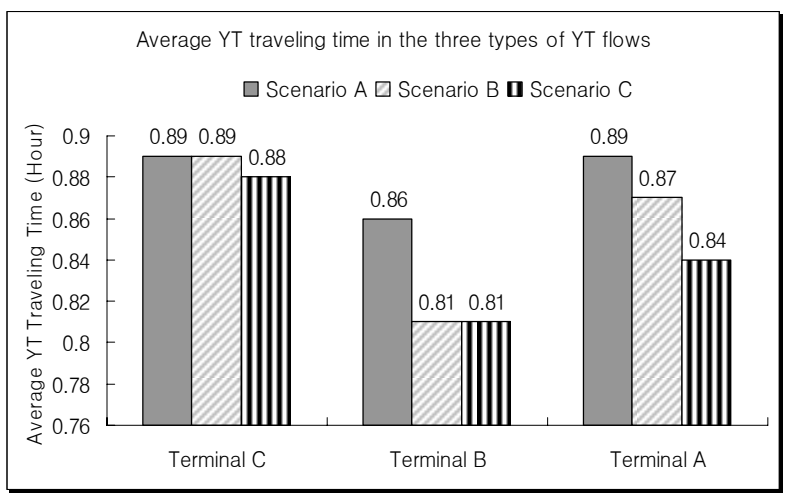

Figure 15: Average YTs Traveling Time

\subsection{Comparing scenarios (D, E) with different numbers of cranes}

This section evaluates effects of the number of rail cranes on the system performance. Simulation results are shown in Figures 16 and 17. In these figures, we found that the crane in the scenario $\mathrm{E}$ has a higher work load and a higher rail occupancy than scenario D. These results demonstrated that the installation of multiple cranes incurred interferences between cranes. The interference increased the work load of rail cranes. And these results also demonstrated that the construction of two rail terminals is more efficient than a single rail terminal.

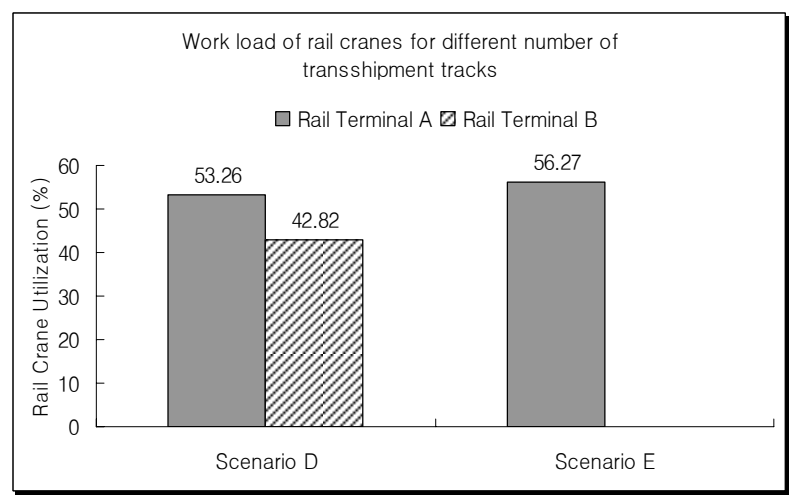

Figure 16: Work Load of Rail Cranes for Different Number of Transshipment Tracks 


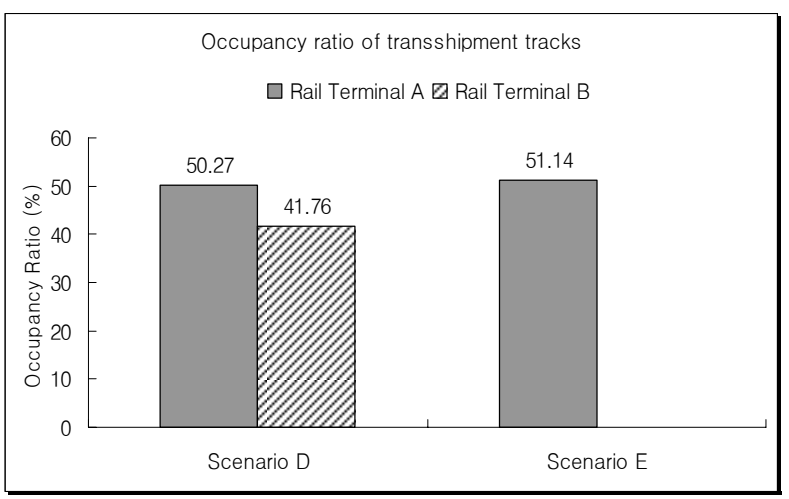

Figure 17: Occupancy Ratio for Different Number of Rail Terminals

\subsection{Comparing scenarios $(F, G, H)$ with different number of tracks}

This section evaluates effects of the number of transshipment tracks on the system performance. Simulation results are shown in Figure 18. In this figure, we found that number of transfer tasks which were not carried out was the smallest in scenario F. This means that by constructing more transshipment tracks, the number of handled containers can increase. However, the difference in the number of containers handled between scenarios $F$ and $G$ was small. Considering the construction cost of a transshipment track is very expensive, scenario $G$ seems to be more practical alternative.

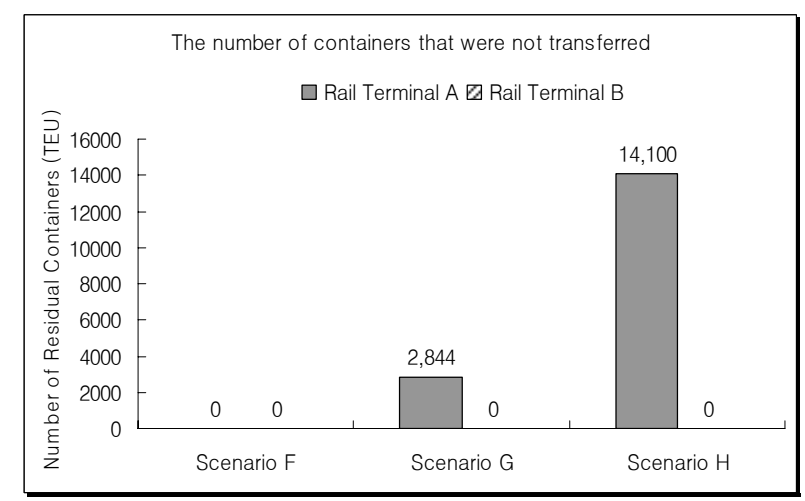

Figure 18: The Number of Unfinished Transfers for Different Number of Transshipment Tracks

\subsection{Final selected layout}

Results of the simulation showed that the YT operation using mixed flows for each container terminal is the most efficient. And the installation of one rail crane at each operation area was selected. Next, the construction of three transshipment tracks at the side of the port and two transshipment tracks at the hinterland side was found to be suitable for rail terminal A. Theses results concluded that the planed layout of rail terminal A in Figure 4 is the most appropriate.

\section{CONCLUSION}

This paper discussed the design issues of rail terminals located near to container ports. First, we introduced a design process for rail terminals. Then, we proposed formulas for estimating design parameters. Finally, a simulation test was performed to evaluate each design alternative. By the experiment results, various suggestions on the design alternative were compared with each other. For rail cranes and YTs, various operation rules were tested. It was found that the simulation is a good tool to complement the design method by using simple formulas which cannot consider stochastic behaviors of the system. Extended research is needed on various operation rules for each type of equipment.

\section{ACKNOWLEDGMENTS}

This paper is a part of the result of the project "Development of Intelligent Port and Logistics System for SuperLarge Container Ships", which was sponsored by Ministry of Maritime Affairs and Fishery in Korea.

\section{REFERENCES}

Alicke, K. 2002. Modeling and optimization of the intermodal terminal Mega Hub, OR Spectrum, 24(1), 1-17.

Ballas, A. and J. Golias 2002. Comparative evaluation of existing and innovative rail-road freight transport terminals, Transportation research Part A, 36(7), 593611.

Corry, P and E. Kozan 2006. An assignment model for dynamic load planning of intermodal trains, Computers \& Operations Research, 33(1), 1-17.

Kim, K.H. and H.B. Kim 2002. The optimal sizing of the storage space and handling facilities for import containers. Transportation Research Part B, 36(9), 821835.

Kozan, E. 2000. Optimising container transfers at multimodal terminals, Mathematical and Computer Modelling, 31(10-12), 235-243.

Steenken, D., S. Voss, and R. Stahlbock 2004, Container terminal operation and operations research - a classification and literature review, OR Spectrum, 26(1), 3-49.

\section{AUTHOR BIOGRAPHIES}

BYUNG KWON LEE is a Ph.D. student in the Department of Industrial Engineering at Pusan National University. His research interests include the optimization of planning and operation systems for port container terminals. 
BONG JU JUNG is a master's degree student in the Department of Industrial Engineering at Pusan National University. He has interests in the logistics systems at rail terminals.

JEONG HOON SEO holds a MS degree from the Department of Industrial Engineering at Pusan National University. He is a simulation researcher at the Digital Factory Research Center in Yeungjin College. He has carried out many industrial simulation projects over 10 years.
SOON OH PARK holds a MS degree from the Department of Industrial Engineering at Pusan National University. He is working at VMS Solutions, Ltd. He has carried out many industrial SI projects over 10 years.

KAP HWAN KIM is working at the Department of Industrial Engineering at Pusan National University. He received Ph.D. and M.S. degrees from the Department of Industrial Engineering of KAIST. His research interests include the design and operation of production planning and control systems, and material handling systems. He has carried out many logistics projects focused on port container terminals. 